\title{
APLIKASI KEAMANAN PESAN MENGGUNAKAN ALGORITMA STEGANOGRAFI DAN KRIPTOGRAFI
}

\author{
Wawan Setiawan, Juwairiah, Herry Sofyan \\ Prodi Teknik Informatika UPN "Veteran" Yogyakarta \\ Jl. Babarsari 2 Tambakbayan 55281 Telp (0274)485323 \\ email : juwai riah@yahoo.com
}

\begin{abstract}
Steganography is a technique of hiding a secret or confidential information in another message so that other people are not aware of the existence of a hidden message. In order for hidden messages or information that it's safer to use the science of cryptography for data encryption. So that the data or messages can not be understood by an unauthorized person who managed to access the data. This application uses methodologies Rappid Guidelines for Application Engineering (Grapple), which consists of Requirement gathering, Analysis, Designs, Development, and Deployment. This application was built using the Java programming language with tools NetBeans IDE 7.0. The algorithm used in this application is the steganography algorithms Least Significant Bit and cryptographic algorithms Vigenere Cipher. The final results of this study is an application of steganography in images by using the method of least significant bit (LSB) and vigenere that can be run on a computer. The image can be used in this application is the image format JPG, PNG, GIF, and BMP. This application can insert text in the image and can perform encryption and decryption at the message you want to insert.
\end{abstract}

\section{Keywords : application, cryptography, steganography, image, LSB, Vigenere}

Steganografi merupakan teknik menyembunyikan pesan atau informasi rahasia ke dalam pesan lain agar orang lain tidak menyadari keberadaan dari pesan yang disembunyikan. Agar pesan atau informasi yang disembunyikan itu lebih aman dapat menggunakan ilmu kriptografi untuk penyandian data. Sehingga data atau pesan tidak dapat dimengerti oleh pihak yang tidak berwenang yang berhasil mengakses data tersebut. Aplikasi ini menggunakan metodologi Guidelines for Rappid Application Engineering (GRAPPLE) yang terdiri dari Requirement gathering, Analysis, designs, Development, dan Deployment. Aplikasi ini dibuat menggunakan bahasa pemrograman java dengan tools NetBeans IDE 7.0. Algoritma yang digunakan dalam aplikasi ini adalah algoritma steganografi Least significant Bit dan algoritma kriptografi Vigenere Cipher. Hasil akhir dari penelitian ini adalah sebuah aplikasi steganografi pada citra dengan menggunakan metode least significant bit (LSB) dan vigenere yang dapat dijalankan pada komputer. Citra yang dapat di digunakan pada aplikasi ini adalah citra berformat JPG, PNG, GIF, dan BMP. Aplikasi ini dapat menyisipkan pesan teks pada gambar serta dapat melakukan proses enkripsi dan dekripsi pada pesan yang ingin disisipkan.

Kata kunci : aplikasi, kriptografi, steganografi, citra, LSB, Vigenere

\section{PENDAHULUAN}

Dengan seiring berkembangannya kemajuan teknologi saat ini, membuat sebuah informasi sangat penting. Bahkan ada yang mengatakan bahwa masyarakat dunia kini sudah berada pada sebuah "information-based society". Sangat pentingnya nilai sebuah informasi menyebabkan seringkali informasi yang ingin disampaikan tidak diterima oleh penerima, melainkan jatuh ditangan orang lain. Untuk mengatasi masalah keamanan informasi tersebut, metode yang bisa digunakan adalah ilmu steganografi dan ilmu kriptografi. Steganografi merupakan teknik menyembunyikan pesan atau informasi rahasia agar orang lain tidak menyadari keberadaan dari pesan yang disembunyikan. Teknik ini menggunakan wadah penampung seperti citra.

Seperti diketahui citra merupakan gambar pada bidang dua dimensi yang dihasilkan melalui proses digitasi. Saat ini peredaran citra di internet sangat banyak sehingga sulit untuk 
menemukan file asli citra tersebut. Untuk menjaga keaslian dari suatu citra, bisa juga menggunakan steganografi. Jadi steganografi tidak hanya bisa digunakan untuk menyembunyikan pesan atau informasi, tetapi juga bisa digunakan sebagai proteksi hak cipta dan keaslian suatu citra.

Least significant bit merupakan metode untuk mengimplementasikan steganografi pada citra, yaitu dengan menggantikan bit-bit citra asli dengan bit-bit informasi yang akan disembunyikan, sehingga hasil keluaran akan sama dengan yang aslinya jika dilihat dengan kemampuan indera penglihatan manusia.

Berbeda dengan steganografi, kriptografi merupakan teknik penyandian data. Dengan teknik kriptografi data disandikan atau di enkripsi menjadi data rahasia sehingga data itu tidak akan berarti apa-apa bagi pihak yang tidak berwenang yang berhasil mengakses data tersebut. Data rahasia yang telah di enkripsi dan di terima oleh penerima dapat di ubah kembali atau dideskripsikan ke data asli sehingga dapat di pahami. Vigenere cipher merupakan salah satu algoritma kriptografi klasik untuk menyandikan suatu plainteks dengan menggunakan teknik substitution.

Penggabungan dua teknik keamanan data yakni kriptografi dengan metode vigenere dan steganografi dengan metode least significant bit diharapkan mampu mengamankan data. Kriptografi berfungsi untuk mengenkripsikan data atau pesan, sedangkan steganografi berfungsi untuk menyisipkan pesan kedalam sebuah citra.

\section{RUMUSAN MASALAH}

Berdasarkan latar belakang di atas, maka dapat dibuat rumusan masalah, yaitu : "Bagaimana membuat aplikasi keamanan pesan yang dapat mengimplementasikan steganografi pada citra dengan metode least significant bit (LSB) dan algoritma kriptografi vigenere?"

\section{BATASAN MASALAH}

Untuk memberikan ruang lingkup yang jelas terhadap suatu objek penelitian, maka dibuat batasan-batasan masalah dalam penelitian ini sebagai berikut :

1. Jenis plainteks yang digunakan adalah dalam bentuk karakter alphabet A - Z .

2. Wadah yang digunakan untuk menyisipkan pesan adalah media dalam bentuk citra atau gambar dengan format bmp, jpg, gif dan png.

3. Hasil file output disimpan dengan format png.

4. Pendeteksian pesan dan keamanan kunci tidak dibahas dalam penulisan skripsi ini.

5. Penelitian ini hanya sampai pada tahap uji coba dan aplikasi bersifat standalone.

\section{METODOLOGI PENELITIAN}

Dalam pengembangan aplikasi ini digunakan metodologi Guidelines for Rappid Application Engineering (GRAPPLE) yang terdiri dari Requirement gathering, Analysis, designs, Development, dan Deployment. Namun pada pada sistem ini hanya sampai pada tahap Development.

\section{DASAR TEORI}

\section{Least Significant Bit (LSB)}

Least significant bit (LSB) merupakan salah satu teknik dalam steganografi. Teknik LSB yaitu menggantikan bit terakhir pada gambar dengan bit yang akan disembunyikan (pesan). Misalkan bit pada gambar dengan ukuran 3 pixel sebagai berikut:

(00111111 11101001 11001000)

(0011111111001000 11101001)

(11000000 0010011111101001$)$

Pesan yang akan disisipkan adalah karakter "A" yang memiliki biner 10000001, stego image yang akan dihasilkan adalah: 
Ada dua teknik yang dapat digunakan pada LSB, yaitu penyisipan secara sekuensial dan secara acak. Penyisipan sekuensial dilakukan berurutan sedangkan penyisipan acak dilakukan dengan memasukan kata kunci (stego key) (Sukmawan, 2002).

\section{Vigenere Cipher}

Vigenere cipher mungkin adalah contoh terbaik dari cipher alphabet-majemuk manual. Algoritma ini dipublikasikan oleh diplomat (sekaligus seorang kriptologis) Perancis, Blaise de Vigenere pada abad 16, meskipun Giovan Batista Belaso telah menggambarkanya pertama kali pada tahun 1553 seperti ditulis di dalam bukunya La Cifra del Sig. Giovan Batista Belaso. Vigenere cipher dipublikasikan pada tahun 1586, tetapi algoritma tersebut baru dikenal luas 200 tahun kemudian yang oleh penemunya cipher tersebut kemudian dinamakan vigenere cipher.

Secara sistematis, misalkan kunci dengan panjang $m$ adalah rangkaian $k_{1} k_{1} \ldots k_{m}$, plainteks adalah rangkaian $p_{1} p_{2} \ldots p_{t}$, dan cipherteks dalah rangkaian $c_{1} c_{2} \ldots c_{t}$, maka enkripsi pada Vigenere Cipher dapat dinyatakan sebagai berikut (Munir, 2006):

$$
\mathrm{c}_{\mathrm{i}}=\left(\mathrm{pi}+\mathrm{k}_{\mathrm{r}}\right) \bmod 26(1 \leq \mathrm{i} \leq \mathrm{t})
$$

$i=r(\bmod m)(1 \leq r \leq t)$ dengan indeks $A=0, B=1, \ldots Z=25$.

Jika panjang kunci lebih pendek dari pada panjang plainteks, maka kunci diulang penggunaanya (sistem periodik). Bila panjang kunci adalah $m$, maka periodenya dikatakan $m$. Sebagai contoh, jika plainteks adalah THIS PLAINTEKS dan kunci adalah SONY, maka penggunaan kunci secara periodik adalah sebagai berikut:

Plainteks : TH I SPLAI NT EKS

Kunci : SONYSONYSONYS

Cipherteks : L V VQHZNGFHRVL

Pada contoh di atas huruf T dienkripsi dengan kunci S menjadi :

$(T+S) \bmod 26=(19+18) \bmod 26=11=L$

Dan huruf $\mathrm{H}$ berikutnya dienkripsi dengan kunci $\mathrm{O}$ menjadi :

$(\mathrm{H}+\mathrm{O}) \bmod 26=(7+14) \bmod 26=21=\mathrm{V}$

Demikian seterusnya untuk huruf plainteks lainya.

\section{ANALISIS DAN PERANCANGAN}

Berdasarkan masalah pada latar belakang, maka diperlukan spesifikasi kebutuhan yang berhubungan dengan kemampuan aplikasi keamanan pesan yang akan dibuat. Tabel 1 menjelaskan daftar kebutuhan pengguna yang akan dibuat dalam bentuk Use Case.

Tabel 1. Kebutuhan Pengguna

\begin{tabular}{|c|l|c|}
\hline No & \multicolumn{1}{|c|}{ Requirement } & Use Case \\
\hline 1 & $\begin{array}{l}\text { Pengguna dapat menulis pesan dan mengenkripsi } \\
\text { pesan }\end{array}$ & Penyandian Pesan \\
\hline 2 & $\begin{array}{l}\text { Pengguna dapat menyisipkan pesan ke dalam sebuah } \\
\text { citra atau gambar }\end{array}$ & Membaca Pesan \\
\hline 3 & $\begin{array}{l}\text { Pengguna dapat membaca atau mengekstrak pesan } \\
\text { yang telah disisipkan di dalam sebuah citra atau } \\
\text { gambar }\end{array}$ & $\begin{array}{l}\text { Penguraian Pesan } \\
\text { diekstrak sebelumnya }\end{array}$ \\
\hline 4
\end{tabular}

Tabel 2 menjelaskan daftar kelas yang akan dibuat. 
Tabel 2. Daftar Kelas

\begin{tabular}{|c|c|c|}
\hline No & Nama Class & Deskripsi \\
\hline 1 & Stego_tampil & $\begin{array}{l}\text { Class ini yang menangani komunikasi antara actor dan komponen internal } \\
\text { sistem, yaitu dalam hal untuk menulis pesan, menyisipkan pesan, } \\
\text { membaca pesan, melihat petunjuk penggunaan aplikasi, about dan keluar } \\
\text { dari sistem, semuanya diakses melalui class stego_tampil. Di dalam class } \\
\text { ini terdapat: Attribute : jmenu steganog, jmenu bantu, jmenuitem encode, } \\
\text { jmenuitem decode, jmenuitem petunjuk, jmenuitem about, jmenuitem exit, } \\
\text { jlabel labeljudul, jbutton decodeButton, jbutton bacapesan, jbutton } \\
\text { cancel1, jbutton back1, jbutton bproses1, jbutton bproses2, jbutton } \\
\text { bproses3, jlabel image_input, jlabel image_input1 dan jlabel } \\
\text { image_output. Operation : public stego_tampil, public image_panel, } \\
\text { public image1_panel. }\end{array}$ \\
\hline 2 & Filter_gambar & $\begin{array}{l}\text { Class ini yang menangani komunikasi antara actor dan komponen internal } \\
\text { sistem, yaitu dalam hal menyaring dan menampilkan format-format } \\
\text { gambar tertentu. Di dalam class in terdapat: Operation : public } \\
\text { filter_gambar, protected filegambar, public Boolean accept, public string } \\
\text { getdecription,protected getextention }\end{array}$ \\
\hline 3 & Steganografi & $\begin{array}{l}\text { Class ini yang menangani penyisipan pesan ke dalam gambar dan } \\
\text { ekstrak pesan dari gambar. Di dalam class ini terdapat: Attribute : teks } \\
\text { dan gambar. Operation : public steganografi, public Boolean encode, } \\
\text { public } \\
\text { string decode, private string image_path, private bufferimage getimage, } \\
\text { private Boolean setlmage, private bufferimage add_text, private byte[] } \\
\text { get_byte_data, private byte[] bit_conversion, private byte[] encode_text, } \\
\text { private byte[] decode_text. }\end{array}$ \\
\hline 4 & Vigenere & $\begin{array}{l}\text { Class ini yang menangani enkripsi dan dekripsi pesan. Di dalam class ini } \\
\text { terdapat: Attribute : key, enkripsi, dekripsi, alphabet, mode, pesan dan } \\
\text { key. } \\
\text { Operation : public vigenere, public string mulai, public } \\
\text { getAlpahebetPosition, private string enkripsi, private string dekripsi. }\end{array}$ \\
\hline 5 & about & $\begin{array}{l}\text { Class ini menampilkan informasi dari pembuat aplikasi. Di dalam class ini } \\
\text { terdapat: Attribute : jlabel gtentang, jlabel tentang, dan jlabel tentang1. } \\
\text { Operation : public about. }\end{array}$ \\
\hline 6 & Petunjuk & $\begin{array}{l}\text { Class ini menampilkan petunjuk penggunaan aplikasi. Di dalam class ini } \\
\text { terdapat: Attribute : jlabel judul dan jtextarea tampil. Operation : public } \\
\text { petunjuk dan fileReader Reader. }\end{array}$ \\
\hline 7 & Stego_aksi & $\begin{array}{l}\text { Class ini yang mengontrol pemanggilan dari semua kelas. Di dalam class } \\
\text { ini terdapat: Attribute : jpanel decode_panel, jpanel tampilG_panel, jlabel } \\
\text { labeljudul. Operation : public stego_aksi, public void exit actionperformed, } \\
\text { public void about actionperformed, public void encode } \\
\text { actionperformed, public void decode actionperformed, public void petunjuk } \\
\text { actionperformed, public void Bproses1actionperformed, public void } \\
\text { decodebutton actionperformed, public void bproses3 actionperformed, } \\
\text { public void bproses2 actionperformed, public void back1 actionperformed, } \\
\text { public void cancel1 actionperformed, public void bukapesan } \\
\text { actionperformed, private void stego_awal, private void decode_view, } \\
\text { private void gambar_view, public void update, public static void main. }\end{array}$ \\
\hline 8 & enkripsi & $\begin{array}{l}\text { Class ini menangani proses enkripsi pesan.Attribute: jbutton submitbtn, } \\
\text { jbutton submitbtn1, jtextarea area1, jtextarea area2, jtextfield txt1, jbutton } \\
\text { submitbtn2. Oction Operation: submitbtn actionperformed, } \\
\text { submitbtn1actionperformed, submitbtn2 actionperformed, update, private } \\
\text { void gambar_view. }\end{array}$ \\
\hline 9 & dekripsi & $\begin{array}{l}\text { Class ini menangani proses dekripsi pesan. Attribute: jbutton submitbtn, } \\
\text { jbutton submitbtn1, jtextarea area1, jtextarea area2, jtextfield txt1. } \\
\text { Operation: submitbtn actionperformed, submitbtn1 actionperformed. }\end{array}$ \\
\hline
\end{tabular}




\section{Perancangan}

Tahap ini dibuat berdasarkan dari tahap analisis. Dalam perancangan dilakukan 2 tahapan yaitu perancangan diagram use case, diagram sequence, diagram activity, struktur menu dan perancangan antar muka (interface).

\section{Diagram Use-Case}

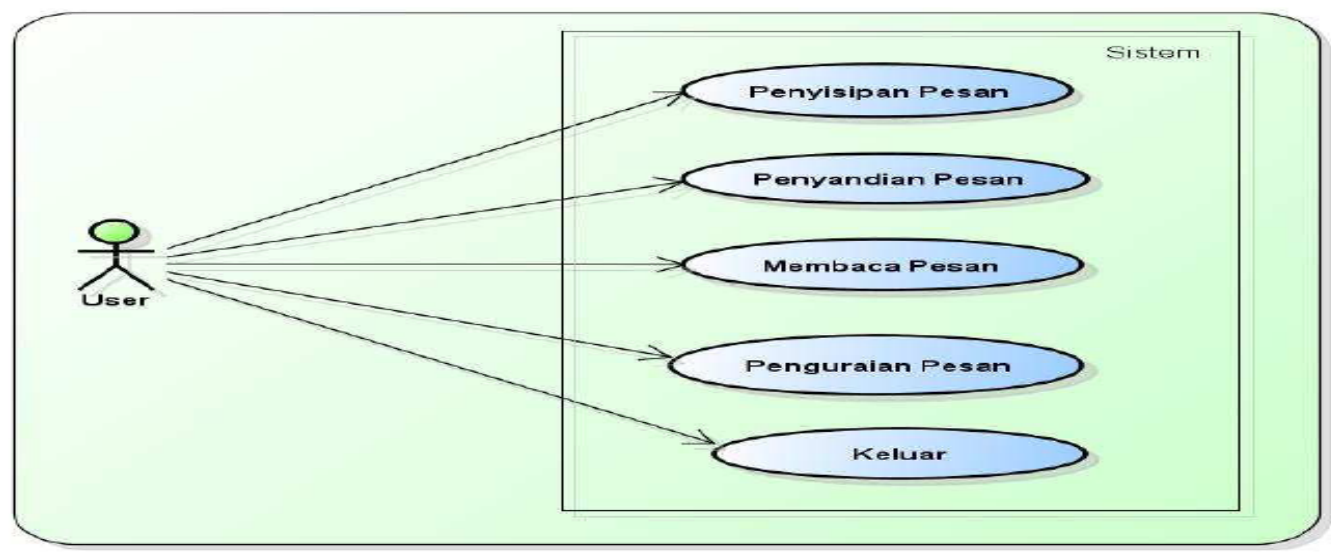

Gambar 1. Diagram Use Case 


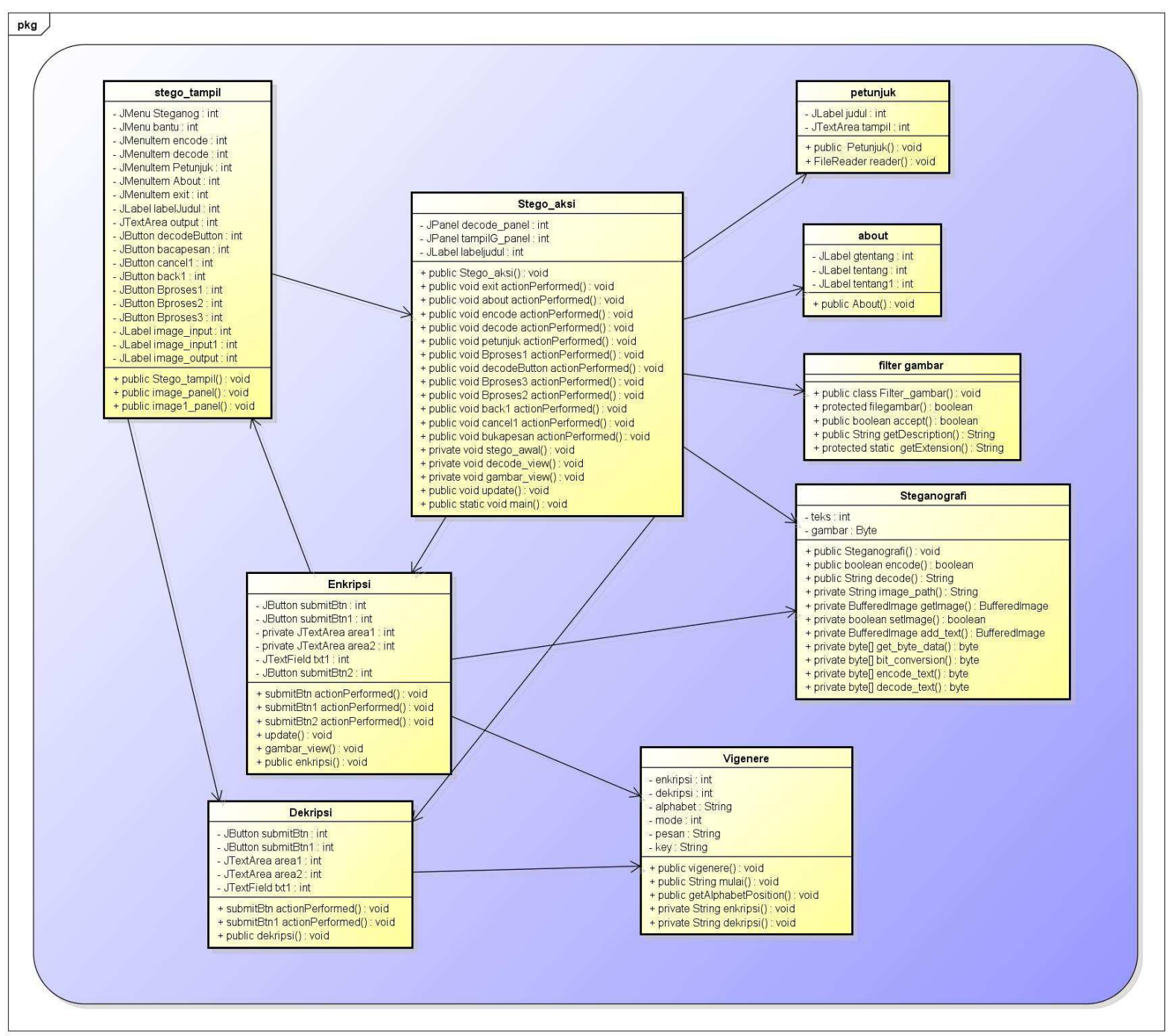

\section{IMPLEMENTASI}

\section{Gambar 2.Diagram Kelas}

Pembahasan dari pembuatan perangkat lunak ini bersifat umum, yaitu menjelaskan method, konstruktor, class dan bagian-bagian utama yang dibuat pada tahap development dan deployment. Bagian utama tersebut dikembangkan dari class-class yang terbentuk dari tahap requirements hingga tahap design. Pada tahap development dilakukan pengembangan dan perbaikan method, konstruktor dan class, agar dapat menghasilkan sistem seperti yang diinginkan. Tahapan deployment merupakan tahapan terakhir pada metode GRAPPLE. Seluruh source code yang telah disusun mulai dari tahapan perancangan hingga development diintegrasikan pada komputer, sehingga seluruh tampilan sistem dapat tampil dan digunakan oleh user.

\section{Form Awal}

Form awal merupakan form utama yang akan tampil setelah aplikasi dijalankan. 


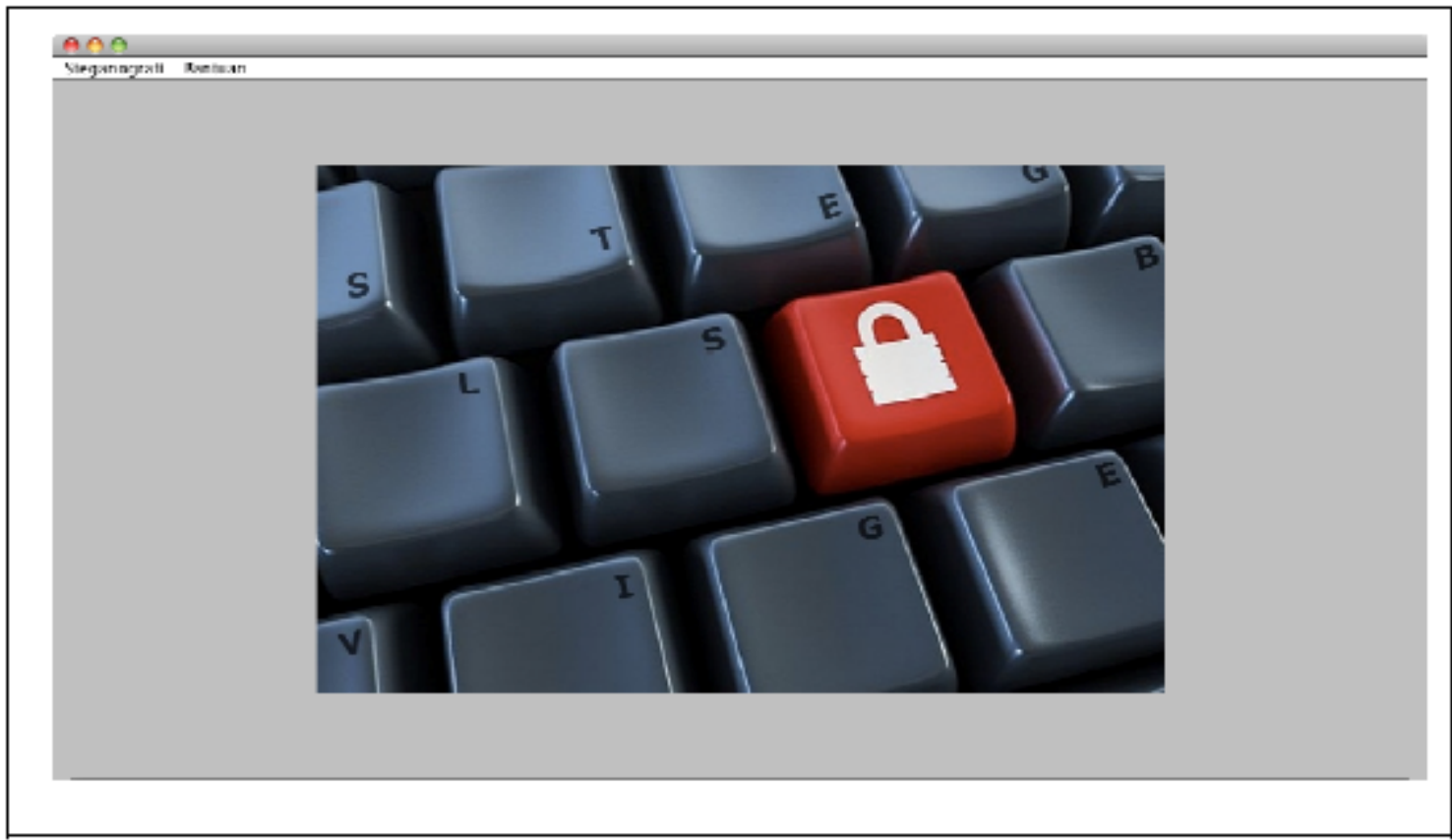

\section{Proses Penyisipan}

Gambar 3. Tampilan Form awal.

Ketika user memilih menu sisip pesan maka akan tampil form open untuk memilih gambar yang akan disisipkan pesan.

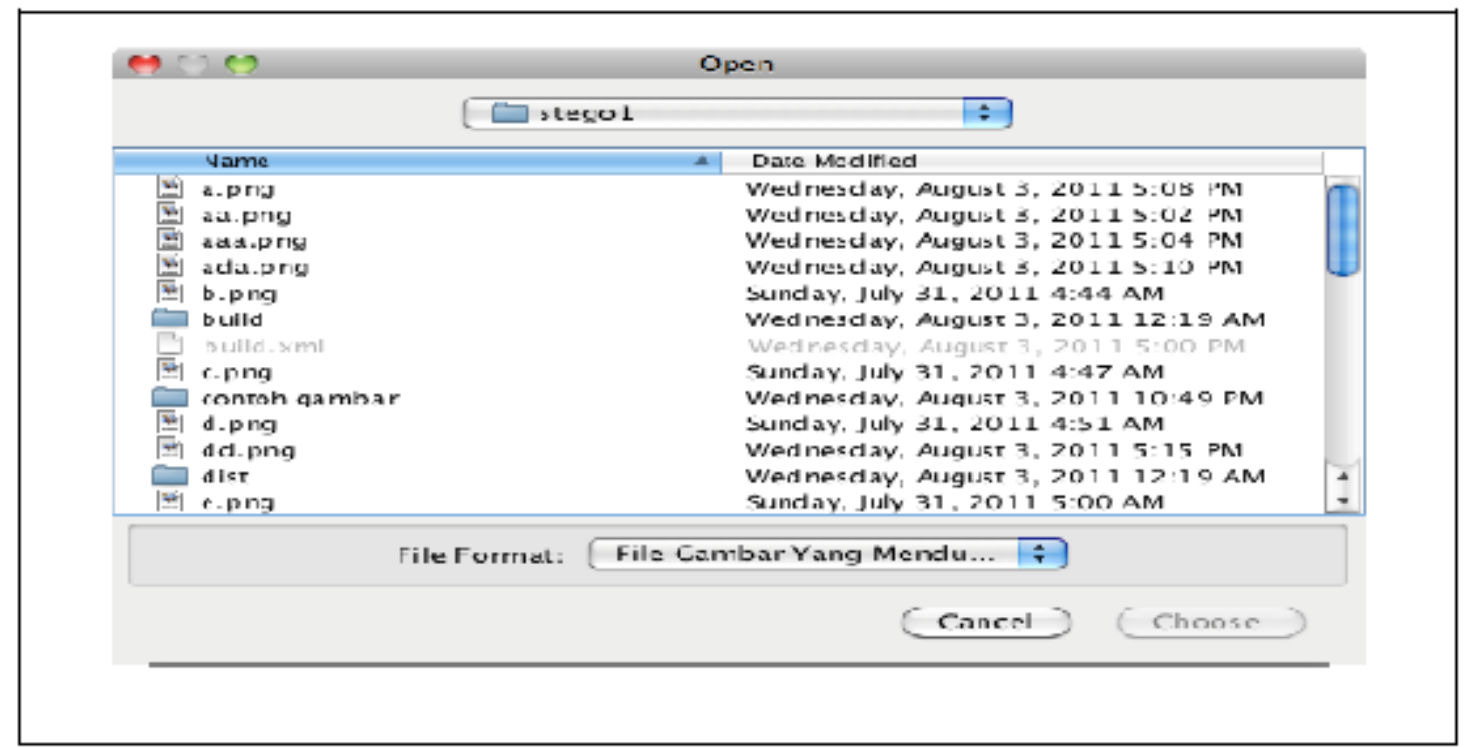

Gambar 4. Tampilän Form Open.

Setelah user memilih gambar maka sistem akan menampilkan gambar di form sisip pesan. 


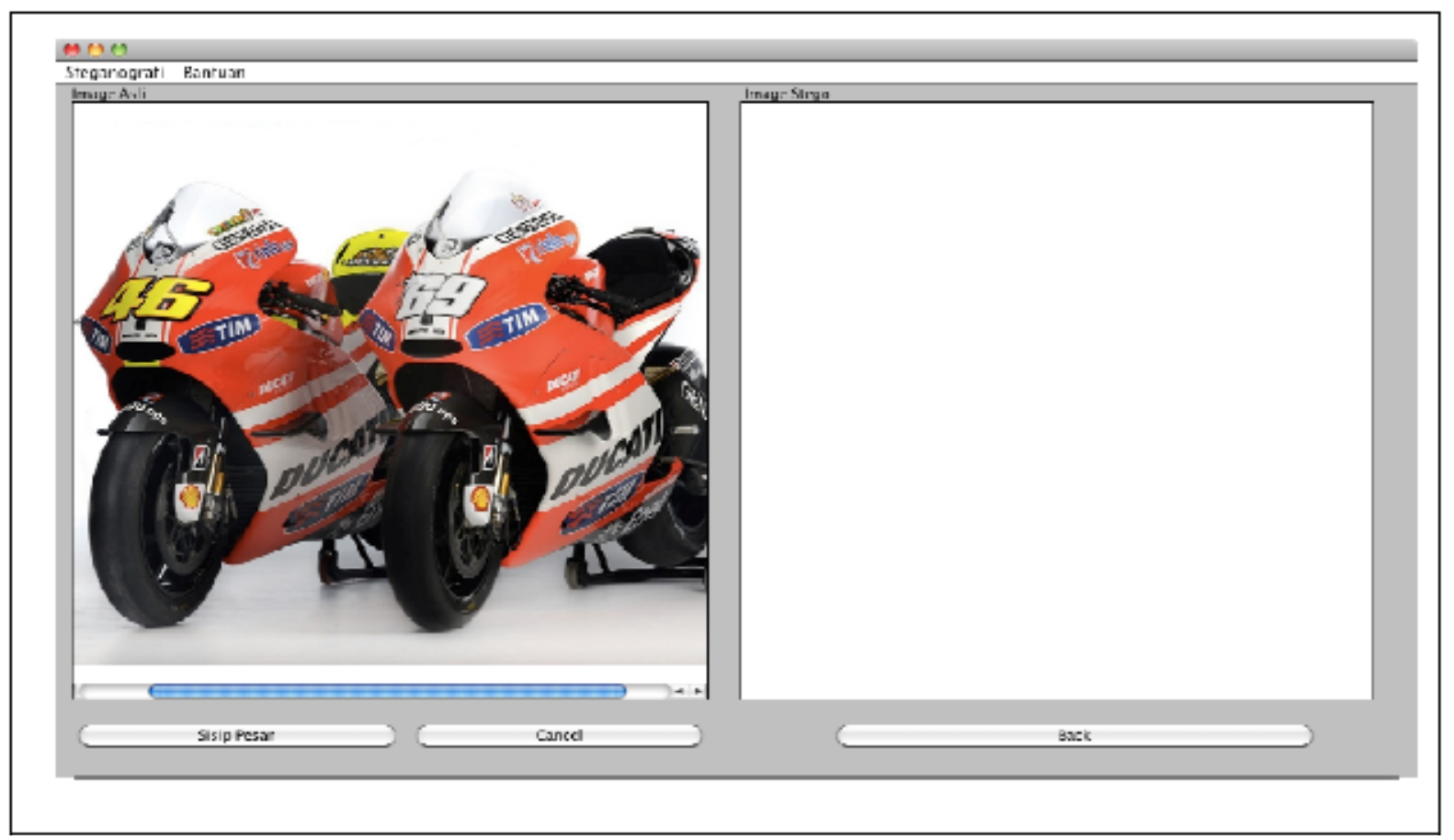

Gambar 5. Tampilan Form Sisip Pesan

Di dalam form sisip pesan terdapat tiga button yaitu button sisip pesan, cancel dan back. Button sisip pesan akan menampilkan form enkripsi, jika button cancel akan menampilkan form open untuk memilih gambar baru dan button back akan kembali ke tampilan awal. Ketika user memilih button sisip pesan yang terdapat di form sisip pesan maka akan tampil form enkripsi.

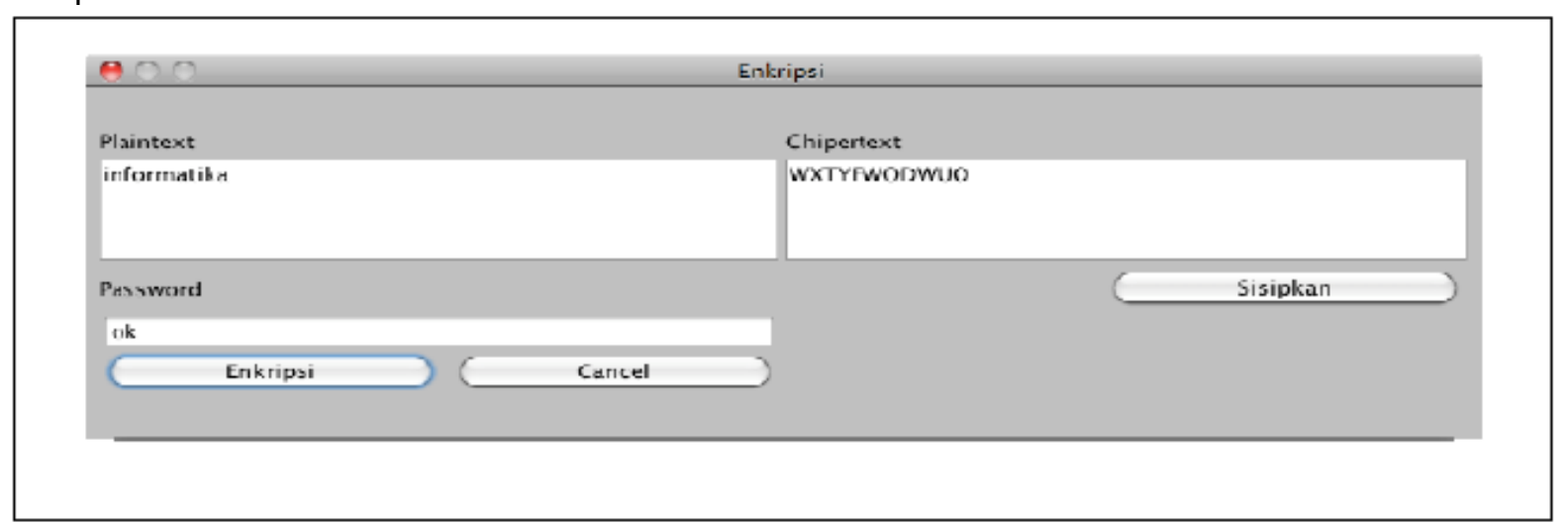

Gambar 6. Tampilan Form Enkripsi

Pada form enkripsi terdapat dua textarea yaitu textarea plaintext dan textarea chipertext, satu textfield yaitu textfield password dan tiga button yaitu button enkripsi, button cancel dan button sisipkan. Setelah user menginputkan pesan dan password maka user harus mengenkripsikan pesan tersebut menjadi pesan chiperteks dengan memilih button enkripsi.

Setelah proses enkripsi pesan selesai, selanjutnya sisipkan pesan chipertext ke dalam gambar yang telah ditentukan sebelumnya dengan memilih button sisipkan. Setelah itu sistem akan meminta user menginputkan nama untuk nama gambar yang telah sisipkan pesan.

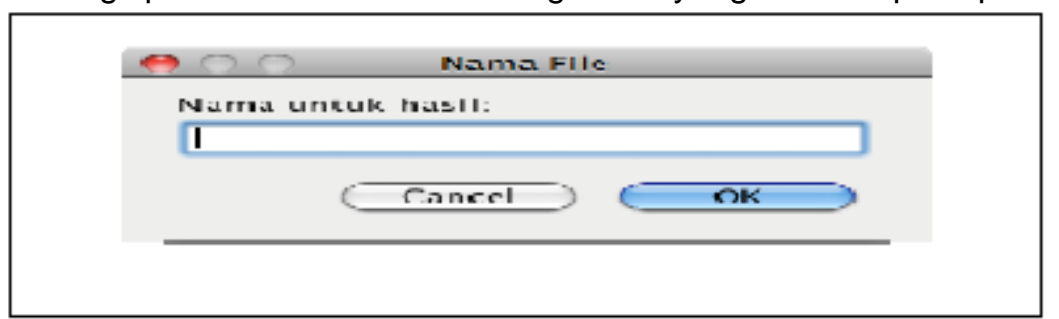

Gambar 7 Tampilan Form untuk Nama Hasil. 
Setelah proses penyisipan selesai, sistem akan menampilkan gambar yang telah disisipkan di dalam form sisip pesan.

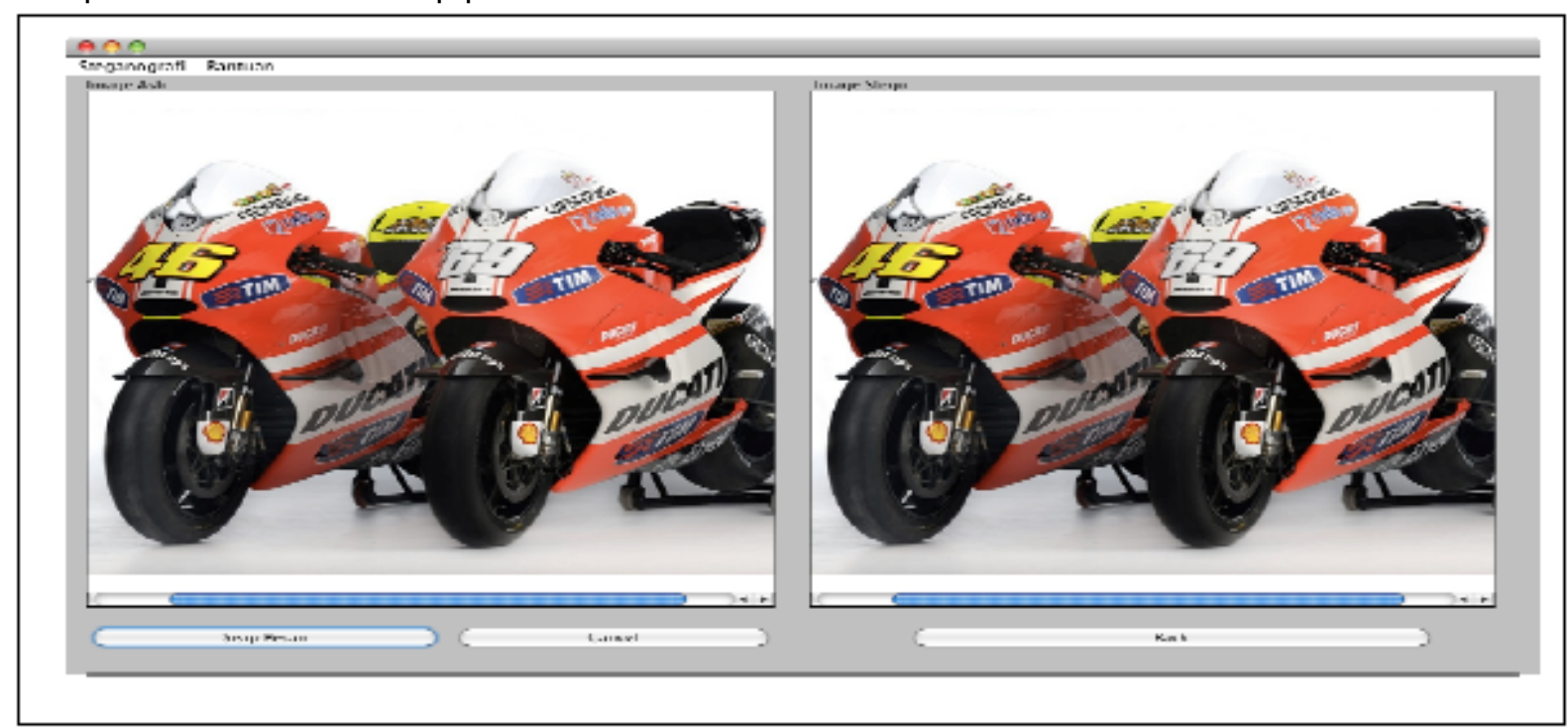

\section{Proses Baca Pesan}

Gambar 8. Tampilan Setelah Proses Penyisipan

Ketika user memilih menu baca pesan maka akan tampil form open untuk memilih gambar steganografi. Setelah user memilih gambar maka gambar yang dipilih akan ditampilkan di form baca pesan.

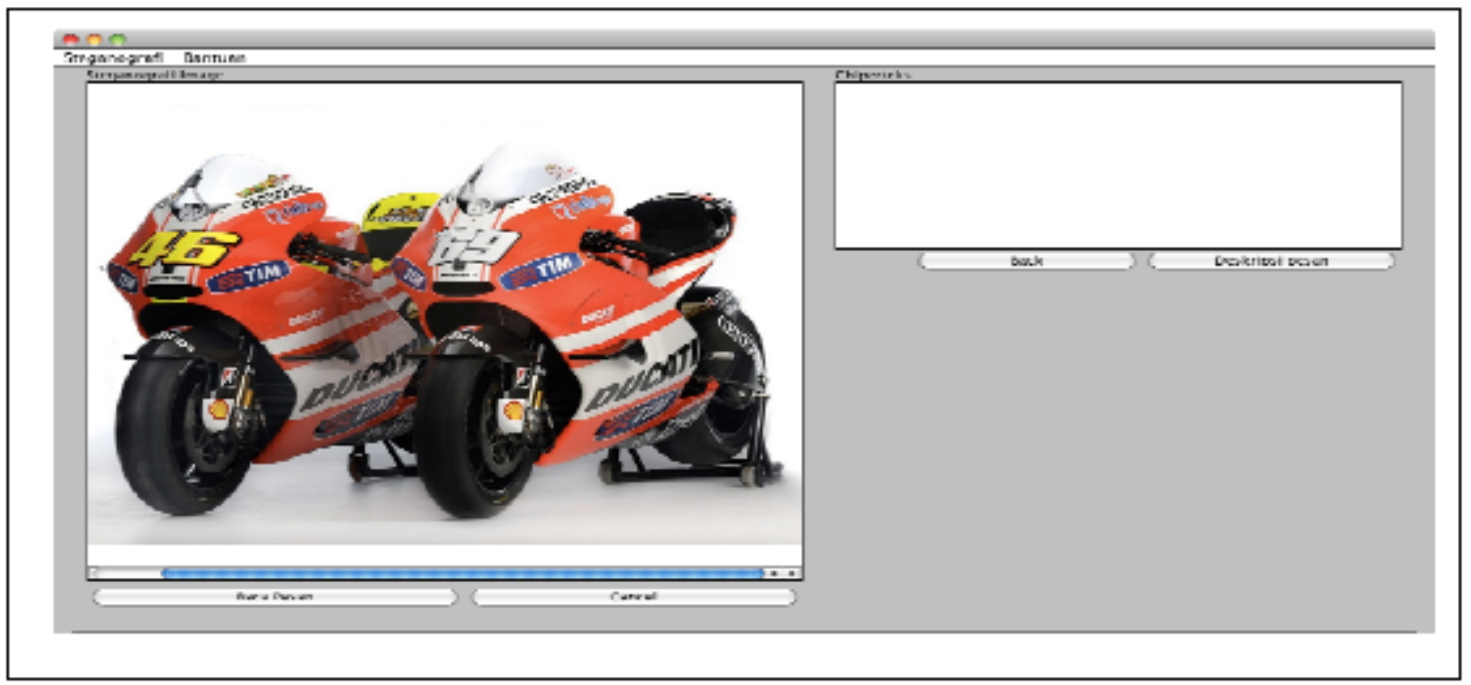

Gambar 9. Tampilan Form Baca Pesan.

Di dalam form baca pesan terdapat empat button yaitu button baca pesan, cancel, back dan dekripsi Pesan. Button baca pesan akan menampilkan pesan yang ada di dalam gambar, jika button cancel akan menampilkan form open untuk memilih gambar baru, button back akan kembali ke tampilan awal dan button dekripsi pesan akan menampilkan form dekripsi.

Ketika user memilih button baca pesan maka sistem akan membaca pesan yang ada di dalam gambar dan menampilkannya di textarea chiperteks. 


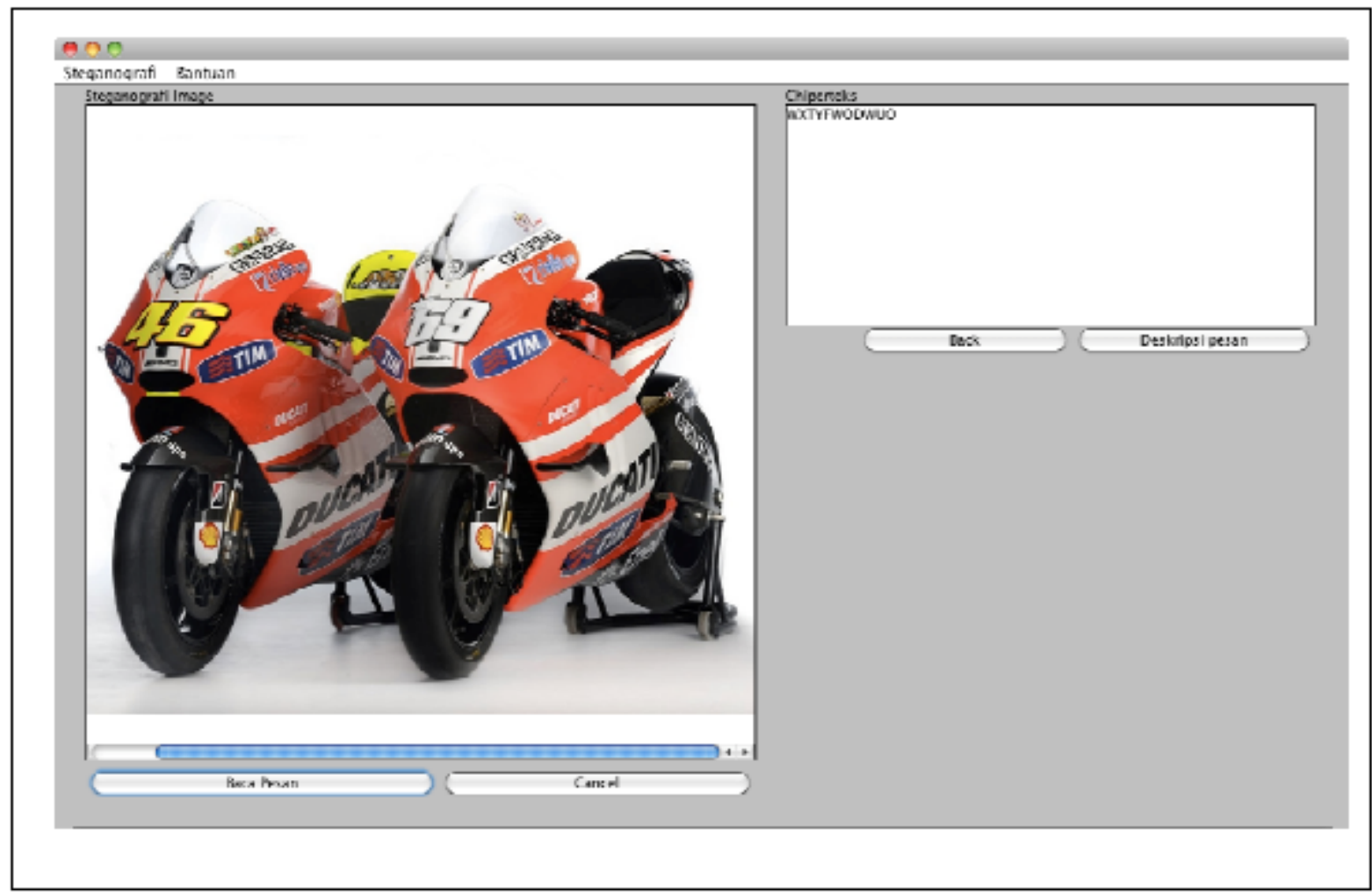

Gambar 10. Tampilan Setelah Baca Pesan.

Setelah proses baca pesan selesai maka user harus memilih button dekripsi pesan agar pesan chiperteks yang ada didekripsikan menjadi pesan plainteks. Ketika button dekripsi pesan dipilih maka sistem akan menampilkan form dekripsi.

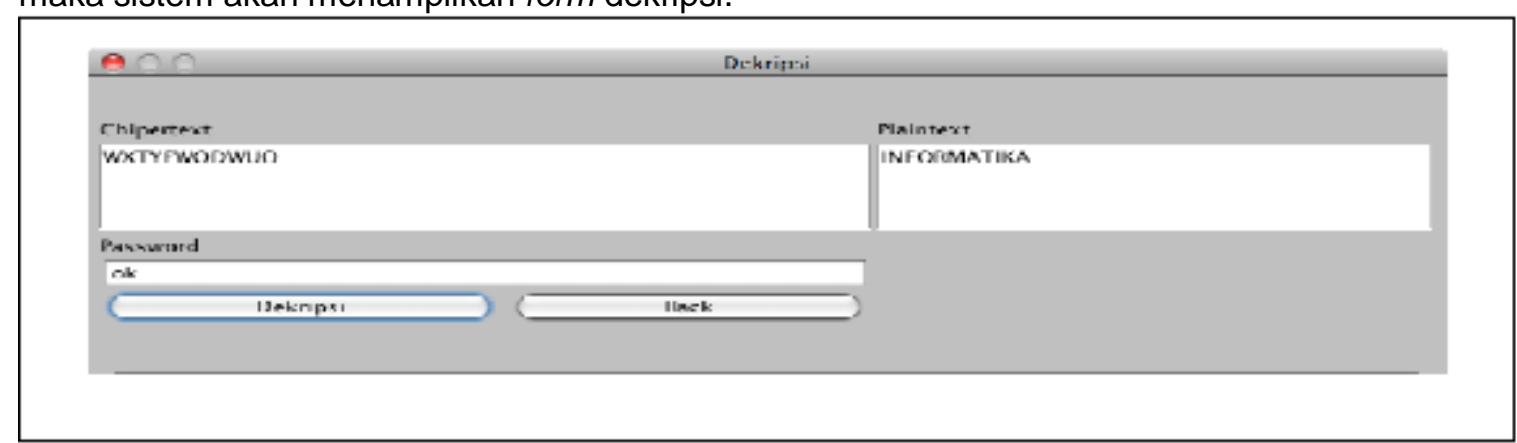

Gambar 11. Tampilan Form Dekripsi.

Pada form dekripsi terdapat dua textarea yaitu textarea chipertext dan textarea paintext, satu textfield yaitu textfield password dan dua button yaitu button dekripsi dan button back. Pada form dekripsi, textarea chipertext otomatis akan terisi oleh pesan yang ada di form baca pesan. Agar pesan chiperteks bisa didekripsikan menjadi plainteks maka user harus menginput password dan memilih button dekripsi.

\section{KESIMPULAN DAN SARAN}

ini adalah:

Kesimpulan yang diperoleh dari analisis perancangan dan implementasi pada penelitian

1. Telah berhasil dibangun sebuah aplikasi steganografi dan kriptografi pada citra dengan menggunakan J2SE dan dapat dijalankan diperangkat komputer.

2. Algoritma yang digunakan dalam aplikasi ini adalah algoritma steganografi least significant bit (LSB) dan algoritma kriptografi vigenere.

3. Aplikasi ini dapat menyisipkan pesan ke dalam sebuah gambar dengan format jpg, png, gif dan bmp. 
Saran

Aplikasi ini dapat dikembangkan oleh peneliti selanjutnya dengan penambahan fasilitas-fasilitas baru seperti:

1. Aplikasi ini dapat dikembangkan dengan menambah algoritma-algoritma lain seperti playfair cipher, DES, RSA dan sebagainya.

2. Aplikasi ini tidak hanya dapat menghasilkan output png, tetapi dapat menghasilkan output dengan format lain.

3. Tampilan interface dan background-nya dapat dibuat lebih menarik dengan menggunakan gradient dan sebagainya. 


\section{DAFTAR PUSTAKA}

Ariyus, Dony, 2006. Kriptografi Keamanan Data dan Komunikasi. Graha IImu. Yogyakarta.

Fowler, M., 2005, UML Distilled Edisi 3 Panduan Singkat Bahasa Pemodelan Objek Standar, Andi, Yogyakarta.

Hermawan, Benny, 2004, Menguasai Java 2 \& Object Oriented Programming, Andi Yogyakarta. Johnson, Neil F. 2001, Information Hiding Steganography and Watermarking - Attack and Countermeasures, Advanced in Information Security, Kluwer Academic Publisher, United State.

Kurniawan, Freddy. 2005. Sistem Digital Konsep dan Aplikasi. Gava Media. Yogyakarta.

Mohanty, S.P, 1999. Watermarking of Digital Images, Indian Institute of Science, india.

Munawar, 2005, Pemodelan Visual dengan UML, Graha IImu, Yogyakarta

Munir, Rinaldi, 2006. Kriptografi. Informatika. Bandung.

Putra, Darma. 2010. Pengolahan Citra Digital. Andi. Yogyakarta.

Rosa A dan Shalahuddin M, 2011, Rekayasa Perangkat Lunak Terstruktur dan Beorientasi Objek, Modula, Bandung.

Schmuller, Joseph, 1999, Teach Yourself UML in 24 Hours, San Publising, Indianapolis.

Sellar, D, 1996, An Introduction to Steganography, http://www.cs.utc.ac.za/courses/cs400w/nis/ paper99/ dsellars/stego.htm.

Sukmawan, Budi, 2002 , Steganografi, http://www.bimacipta.com/stegano.htm.

http://astah.change-vision.com/en/index.php. (diakses 5 April 2011)

http://ilmukomputer.org/2007/02/27/netbeans-open-source-java-ide-berbasiskan-swing. (diakses 5 April 2011) 